\title{
Meios de hospedagem como signo de hospitalidade urbana ${ }^{1}$
}

\author{
Lodgings as sign of urban hospitality
}

\section{Instalaciones de alojamiento como signo de hospitalidad urbana}

\author{
Luciano Torres Tricárico \\ Josildete Pereira de Oliveira ${ }^{3}$ \\ Diva de Mello Rossini ${ }^{4}$
}

\begin{abstract}
Resumo: Propósito justificado do tema: Estudos podem demonstrar o papel do espaço para a hospitalidade; sobretudo para a hospitalidade urbana. No entanto, a associação do espaço citadino enquanto imagem e paisagem urbanas dos meios de hospedagem como atributo de hospitalidade urbana, ainda não está devidamente contemplada por bibliografia do referido tema. Objetivo: $\mathrm{O}$ objetivo dessa pesquisa é sistematizar a hospitalidade em meios de hospedagem, a qual foi construída potencialmente a partir de espaços internos dos meios de hospedagem, mas que pode ser observada também à escala da cidade, portanto o meio de hospedagem como fator de hospitalidade urbana - ideia pouco efetivada por bibliografia especializada. Metodologia/Design: Para tanto, a pesquisa se caracterizou como exploratória, respaldada pelo levantamento e leitura bibliográficos, bem como estudos de caso e análises empíricas feitas à luz do ideal de representação (semiótica peirceana). Na seleção do que se pretende representar, é possível identificar uma intelecção, por parte do sujeito emissor (arquitetura de meios de hospedagem), em propor ideologias; e como tal, a arquitetura de meios de hospedagem também pode ser signo de hospitalidade urbana. O método interpretativo de avaliação dos resultados esteve amparado pelas teorias de hospitalidade urbana, essencialmente com o trabalho de Lucio Grinover (2007), que se ampara nas teorias de urbanização acerca de imagem e paisagem urbanas nos trabalhos de Kevin Lynch (2010). Resultados e originalidade do documento: Os resultados inferem sobre a possibilidade da hospitalidade urbana ou da cidade, construída através de meios de hospedagem.
\end{abstract}

Palavras-chave: Meios de hospedagem. Hospitalidade urbana. Cidade.

Abstract: Justification of the topic: Studies can demonstrate the role of space for hospitality; especially for urban hospitality. However, the association of the city space as urban image and landscape of the lodgings as

${ }^{1}$ Artigo oriundo de pesquisa financiada pelo CNPq (Conselho Nacional de Desenvolvimento Científico e Tecnológico - Brasil).

2 Universidade do Vale do Itajaí (UNIVALI), Balneário Camboriú, SC, Brasil. Concepção e desenho do trabalho científico, identificação do problema de pesquisa, construção da metodologia, construção da fundamentação teórica, coleta dos dados, formulação dos resultados, redação do trabalho.

3 Universidade do Vale do Itajaí (UNIVALI), Balneário Camboriú, SC, Brasil. Construção da fundamentação teórica e referencial teórico.

${ }^{3}$ Universidade do Vale do Itajaí (UNIVALI), Balneário Camboriú, SC, Brasil. Construção da bibliometria.

Artigo recebido em: 03/09/112017. Artigo aprovado em: 26/10/2017. 
an attribute of urban hospitality, is not yet adequately contemplated by a bibliography of this theme. Purpose: The objective of this research is to systematize the hospitality in lodgings, which was potentially constructed from internal spaces of lodgings, but can also be observed on the scale of the city, therefore the lodging as a factor of urban hospitality - yet little systematic for thematic bibliography. Methodology/Design: Therefore, the research is characterized as exploratory, supported by bibliographic survey and reading, as well as case studies and empirical analyzes made in light under of the ideal representation (Peirce's semiotic). In the selection of what is to represent, it is possible to identify a intellection, by the subject issuer (lodgings architecture), propose ideologies; and as such, the architecture of lodging can be a sign of urban hospitality. The interpretive method of evaluation of the results was supported by the theories of urban hospitality, especially with the work of Lucio Grinover (2007) who seek refuge in the urbanization theories about image and urban landscape in Kevin Lynch's work. Findings and originality: The results infer about the possibility of urban hospitality or of the city built through of lodgings.

Keywords: Lodgings. Urban hospitality. City.

Resumen: Propósito justificado del tema: Estudios pueden demostrar el papel del espacio para la hospitalidad; sobre todo para la hospitalidad urbana. Sin embargo, la asociación del espacio de la ciudad como imagen urbana y paisaje urbano de los medios de hospedaje como atributo de hospitalidad urbana, aún no está debidamente contemplada por bibliografía de dicho tema. Objetivo: El objetivo de esta investigación es sistematizar la hospitalidad en instalaciones de alojamiento, que fue construida en realidad a partir de los espacios internos de las instalaciones de alojamiento, pero también se puede observar en la escala de la ciudad, por lo tanto la instalación de alojamiento como factor de hospitalidad urbana - idea poco difundida por la bibliografía temática de hospitalidad urbana. Metodología/Design: Por lo tanto, la investigación se caracteriza como exploratoria, con el apoyo de revisión bibliográfica, así como estudios de casos y análisis empíricos hechos a la luz del ideal de la representación (semiótica peirceana). En la selección de lo que se quiere representar es posible identificar una intelección, por parte del emisor (arquitectura de instalaciones de alojamiento), en proponer ideologías; y como tal, la arquitectura de instalaciones de alojamiento también puede ser signo de hospitalidad urbana. El método de interpretación de la evaluación de los resultados fue apoyado por las teorías de la hospitalidad urbana, especialmente con la obra de Lucio Grinover (2007) que ha buscado apoyo en las teorías de urbanización sobre la imagen urbana y el paisaje urbano con el trabajo de Kevin Lynch (2010). Resultados y originalidad del documento: Los resultados pueden inferir la posibilidad de la hospitalidad urbana o de la ciudad, construida a través de las instalaciones de alojamiento.

Palabras-Clave: Instalaciones de alojamiento. Hospitalidad urbana. Ciudad.

\section{INTRODUÇÃO}

Encontra-se um novo momento denominado por muitos por uma era pósmoderna; justificando-se, de forma generalizante e em determinados contextos, um padrão demográfico consolidado pela meIhoria da qualidade de vida e condições mais fácies de sobrevivência; seja através da saúde com seus avanços, seja por conquistas trabalhistas, seja pela garantia de uma aposentadoria, entre outras formas de amparo social. Isso tudo também pode ser relacio- nado com a atividade turística, onde um meio de hospedagem (para um hóspede no gozo das férias, por exemplo) pode ser meIhor "desenhado", não só enquanto suporte do conforto, mas também como experiência estética, eficiência operacional na oferta de serviços e em equidade ambiental para com o local e a comunidade onde se implanta tal meio de hospedagem (Dias, 1990, p. 147).

De sorte que tais situações descritas acima podem ser sistematizadas por teorias de hospitalidade e sustentabilidade (por exemplos) dos espaços em meios de hospe- 
dagem. Lash e Urry (2002) inferem acerca do papel do espaço quando o olhar tem papel fundamental na experiência da viagem.

No entanto, as pesquisas em hospitalidade têm se concentrado essencialmente no papel social dos sujeitos envolvidos, analisando uma variedade de domínios e setores independentes de classes sociais (Gibson \& Molz, 2016; Bastos \& Rejowski, 2015; Lashley, Lynch, \& Morrison, 2007; Camargo, 2015; O'Gorman, 2007). Tasci e Semerad (2016) afirmam que na hospitalidade a "intensa" interação social entre anfitrião e hóspede põe o ingrediente humano como essencial na experiência do hóspede; sobretudo porque é no valor humano que se cria um produto especial.

Os conteúdos sociais dos estudos em hospitalidade chegam a tomar os clientes (hóspedes) como agentes controladores e até executores do planejamento e da gestão das empresas do ramo turístico e hoteleiro, na lógica contemporânea da co-criação (Roeffen \& Grissemann, 2016).

Para Knutson, Beck, Kim e Cha (2009) a questão da hospitalidade se entende pelo necessário envolvimento de pessoas, e não nas "coisas" (entendendo-as como objetos e o espaço).

Portanto, contemporaneamente, o estudo da hospitalidade nos meios de hospedagem não tem efetivamente se pautado nos valores espaciais como mote das investigações; mas, essencialmente, na sua lógica empresarial de cunho social (Lashley, 2015), porque até mesmo a antiga hospitalidade 5 é

\footnotetext{
${ }^{5}$ Segundo Raffestin (2013) a idéia de hospitalidade surgiu na Antiguidade, sendo registrada em textos de Homero e Heródoto; quando o ideal de hospitalidade se encontra registrado na Odisséia de Homero, foi entendida como responsabilidade dos lares
}

uma fundamentação para ajudar a entender e a atender necessidades de clientes, no sentido de que se sintam bem recebidos numa "moralidade" da oferta de alimento, bebida e abrigo. Pezzotti (2011), da mesma maneira, infere que a hospitalidade é a estratégia e o serviço a sua tática.

Lashley (2015) elenca contemporaneamente cinco atitudes hospitaleiras: motivação oculta (no sentido de se obter algum benefício), motivação restritiva (para manter o "inimigo" por perto e controlar suas ações ofensivas), motivação comercial (tratando muito bem o hóspede como um "cliente" na "residência" do anfitrião), motivação recíproca (para receber o mesmo tratamento quando o anfitrião se torna hóspede), motivação redistributiva (por ser generoso ou benevolente), motivação altruísta (por ser "agradável" aos outros). Compreende-se, portanto, um atributo efetivamente social nas motivações de Lashley (2015) que é próprio à hospitalidade, sem dúvida; mas que não tomam o espaço como dominante interpretativa; ainda que uma relação dialética sócio-espacial (Soja, 1993; Lefebvre, 1991) possa se expressar.

Neste sentido, Pitt-Rivers (2012) infere acerca de relações sociais de hospitalidade em que o anfitrião recebe o hóspede com generosidade, anfitrião e hóspede se

nobres, sua ação enfatiza o bem-estar do hóspede e do anfitrião; e este último adquire prestígio e respeito perante a comunidade na qual se insere. A hospitalidade foi registrada também no judaísmo e depois no cristianismo como uma forma de lei. A hospitalidade está assimilada na cultura, ainda que renovada em diferentes épocas; mas, na atualidade, está essencialmente associada à noção de receptividade e acolhimento (Raffestin, 2013, p. 167), portanto envolvendo sujeitos; o que desdobram (inevitavelmente) estudos de cunho social. 
respeitam e se homenageiam mutuamente, mas que o hóspede respeita o anfitrião sobre o uso do espaço. Valores espaciais muitas vezes não são apreensíveis e "mensuráveis" a partir de dados quantitativos; nesse intuito, Oh e Jeong (2010) demonstraram que em diferentes segmentos do mercado de hospedagem se deve depositar maior confiança em teorias do que em dados.

Muitas das pesquisas atuais até interpretam o espaço como signo de hospitalidade na escala citadina; mas, na maior parte das vezes, a motivação da pesquisa passa pelo viés social, empresarial e da gestão de negócios hoteleiros e turísticos. Assim, o destino turístico é interpretado à luz da satisfação do cliente com perfil adequado ou não para aquele destino estudado (Hosany \& Martin, 2012); a imagem do destino é estudada a partir da escolha que o viajante faz antecipadamente da imagem do destino (Ahn, Ekinci, \& Li, 2013; Kamins \& Grupta, 1994); a "felicidade" da experiência turística e a percepção da hospitalidade são interpretadas pela imagem do destino turístico como parte contribuinte de uma análise social predominante (Hatfield, Cacioppo, \& Rapson, 1994).

Por isso há uma série de autores que fazem a crítica a um viés interpretativo de "mão única" para a hospitalidade se tomando dados quantitativos, da percepção do cliente num intuito de averiguações da eficiência empresarial do planejamento e da gestão nos negócios turísticos e hoteleiros: há um "fio condutor" nos estudos de hospitalidade dado à importância ao acolhimento do indivíduo no intuito de atendimento das suas necessidades fisiológicas, psicológicas e sociais; tendo em vista um consumidor satis- feito em sua experiência de viagem (Bareham, 2004; Hemmington, 2007; Nailon, 1982; Carvalho, Salazar, \& Neves, 2011; Gouveia, 2013; Gentile, Spiller, \& Noci, 2007).

Ora, verifica-se então um primeiro problema de pesquisa: a falta em tomar o espaço como signo primordial para os estudos em hospitalidade dos meios de hospedagem. E mais, como um segundo problema de pesquisa demonstrado pelo levantamento bibliográfico que se apresenta na Fundamentação teórica: não há a associação do espaço do meio de hospedagem como hospitalidade urbana; ou seja, o espaço do meio de hospedagem sempre foi tratado como hospitalidade somente na escala interior da edificação ou na oferta de serviços hoteleiros.

Diante destes dois problemas, arriscou-se que a hipótese dessa pesquisa está na revelação da arquitetura de meios de hospedagem como possível signo e atributo de hospitalidade urbana, à escala da cidade. Justifica-se a pesquisa, portanto, pela carência bibliográfica em associar o meio de hospedagem (também) como hospitalidade urbana.

Para tanto, coube uma "varredura" da condição de hospitalidade na história dos meios de hospedagem. O percurso metodológico compreendeu a interpretação da edificação dos meios de hospedagem à escala da cidade, como paisagem urbana. Tais meios de hospedagem foram elencados a partir de sugestões amparadas em bibliografia, em estudos de caso e na divulgação de meios de hospedagem em mídias do trade turístico.

Notou-se, a partir das representações dos meios de hospedagem na imagem e 
paisagem urbanas, o quanto eles são significativos (pelo diferencial na imagem da cidade), criam lugares como referência urbana; e por isso, segundo as teorias de Lucio Grinover (2007), podem ser interpretados como atributos para a hospitalidade urbana.

Justifica-se a relevância desse estudo para o turismo porque abordou dois fenômenos que são intrínsecos a ele: meios de hospedagem e hospitalidade urbana. Entende-se que os meios de hospedagem são para um destino citadino parte efetiva da cadeia produtiva do turismo, sendo ainda considerados parte de infra-estrutura turística (Amposta, 2015).

Já a hospitalidade urbana se fundamenta para o turismo com estudos vinculados às Ciências Sociais Aplicadas e às Ciências Humanas, demonstrando que toda e qualquer ação social no deslocamento e movimento de pessoas, para obtenção do êxito, deve entender e atender conteúdos de hospitalidade; sugere-se, portanto, que o planejamento e a gestão de qualquer atividade turística estão diretamente ligados à aplicação de preceitos de hospitalidade (sendo a hospitalidade urbana uma das vertentes), aos preceitos de bem "acolher" ao outro, à capacitação de pessoas para atividades turísticas no trato com o estrangeiro e com a alteridade (Camargo, 2005; Grinover, 2006).

De modo que dentre as diversas áreas de estudo da hospitaliade, a hosptitaliade urbana foi destacada por essa pesquisa por entender que ela está relacionada com a qualidade do ambiente urbano do destino turístico, com a qualidade da experiência ótica do turista ao se deslocar pela cidade visitada e, portanto, com a qualidade da paisagem urbana do destino turístico citadino (o que inclui uma imagem de cidade também hospitaleira para o cidadão) (Grinover, 2007; Grinover, 2006; Grinover, 2003). E eis que se arriscou aqui que os meios de hospedagem podem contribuir para a formação da imagem e paisagem urbanas de um destino turístico citadino considerado (então) como hospitaleiro.

De modo que o artigo se organiza inicialmente descrevendo tal metodologia adotada; constrói um referencial teórico para o entendimento de hospitalidade do espaço em meios de hospedagem; logo depois se faz a demonstração de que os conteúdos de hospitalidade do espaço em meios de hospedagem estão essencialmente vinculados aos serviços e espaços internos dos edifícios que encerram esses meios de hospedagem. Confronta-se, na discussão dos resultados, diante desse ideal predominante da hospitalidade dos meios de hospedagem, que a hospitalidade de um meio de hospedagem também pode se dar à escala da cidade. De maneira que o resultado obtido é a possibilidade de desdobramentos de pesquisas que procurem demonstrar a contribuição dos meios de hospedagem como hospitalidade na imagem e paisagem urbanas.

\section{METODOLOGIA}

Caracterizou-se por uma pesquisa essencialmente exploratória e descritiva, pois, de acordo com Gil (2008), nos objetivos dessa pesquisa, procurou-se obter uma visão generalizante de um fenômeno: meios de hospedagem como signo de hospitalida- 
de urbana, ao mesmo tempo em que descreve as características desse fenômeno.

Pode-se ainda inferir que o caráter exploratório da pesquisa também se adequa ao valor interdisciplinar porque pretendeu "aproximar" dois fenômenos (meios de hospedagem e hospitalidade urbana) até então nunca antes correlacionados, pouco estudados e sistematizados conjuntamente, permitindo-se a interação entre dois campos do saber, recombinando-se elementos distintos constituintes para uma nova ideia; ainda que seja apresentada, num primeiro momento, de maneira "ampla" e "aberta" (Vasconcelos, 2002).

O caráter exploratório da pesquisa foi respaldado pelo levantamento e leitura bibliográficos, bem como estudos de caso e pesquisa de divulgação de meios de hospedagem pelo trade turístico; houve a necessidade de busca de informação em sítios eletrônicos que fazem a propaganda hoteleira - eis os instrumentos de coleta de dados constituindo-se em material para "leitura" espacial dos ambientes hoteleiros, sobretudo como espaços urbanos, imagem urbana e paisagem urbana.

Entendeu-se que a etapa de coleta de dados foi amparada por repertório adquirido dos pesquisadores, fundamentandose no que Roland Barthes (1971) compreende por experiência e conhecimento prévio do pesquisador na seleção dos materiais considerados pertinentes ao tema de estudo; ou seja, também um acúmulo de conhecimento empírico como dado a ser considerado.

Houve também um momento de verificação dos conceitos de hospitalidade, hospitalidade dos meios de hospedagem e hospitalidade urbana; o uso desses termos em inglês, bem como a combinação deles entre si enquanto palavras-chave (e keywords), para a busca da produção científica relacionada ao tema nos últimos cinco anos (2012 a 2017) em portais de pesquisa acadêmica de base de dados: Ebscohost, Elsevier, Scielo (Scientific Electronic Library Online) e Portal de Periódicos Capes.

Soma-se a isso uma "varredura" de produção científica (com os mesmos termos utilizados na busca dos portais virtuais) na biblioteca da Escola de Comunicação e Artes (ECA) da Universidade de São Paulo (USP), na biblioteca da Faculdade de Arquitetura e Urbanismo (FAU) da Universidade de São Paulo (USP), na biblioteca da Universidade do Vale do Itajaí (UNIVALI) e na biblioteca da Universidade Anhembi-Morumbi (UAM), tendo-se assim um elenco essencialmente pautado por livros, teses e dissertações sobre $o$ assunto.

A busca em portais de base de dados e nas bibliotecas conferiu um levantamento bibliométrico como parte e processo da pesquisa, necessário para a indicação da bibliografia a ser utilizada na identificação do problema de pesquisa, na construção do referencial teórico e para a fundamentação teórica. Sobretudo, a bibliometria confirmou a lacuna existente, o caráter inovador da pesquisa e a contribuição dela para o campo do turismo: o meio de hospedagem nunca antes havia sido associado como atributo e signo de hospitalidade urbana.

Com todo esse material e repertório, seguiu-se à "leitura" espacial do objeto de estudo.

A "leitura" espacial se apoiou no método interpretativo da representação (con- 
forme a semiótica peirceana). Ou seja, entenderam-se as imagens de divulgação e os espaços dos hotéis em meio urbano como representação. Na seleção do que se pretende representar, foi possível identificar uma intelecção, por parte do sujeito emissor ou objeto emissor (arquiteturas de meios de hospedagem), em propor ideologias; as quais, neste sentido, foram interpretadas como signo para criar diferenças na imagem e paisagem urbanas.

Ao se representar, os meios de hospedagem indicam ideologias de um emissor e, possivelmente interpretadas pelo receptor, indicam-se os valores deste; considerando-se que nos processos de emissão e recepção a informação gerada pelo receptor não compreende numa total comunicação e informação; daí também a possibilidade de interpretar a razão pela qual não se deu o objetivo emitente. Nesses processos de representação (emissão e recepção) se revela o repertório cultural dos sujeitos e objetos (meios de hospedagem), podendo-se produzir signos que, associados, puderam reconsiderar hipóteses formuladas no início da pesquisa; permitindo-se possíveis generalizações ou interpretações próprias à linguagem visual e espacial plurissignificativa preconizada pela semiótica peirceana.

De modo que as arquiteturas de meios de hospedagem, enquanto imagem urbana, foram entendidas como representação de lugares na cidade ou como marcos urbanos; ou seja, são elementos visuais "fortes" guardados na memória individual ou coletiva como referenciais no meio urbano (tanto para turistas como cidadãos). Por isso, se os meios de hospedagem são compreendidos como marcos urbanos, pode ser interpretado como dotado de signos de hospitalidade urbana (Grinover, 2007).

Enquanto possíveis generalizações e caráter inovador dessa pesquisa há a possibilidade de se vislumbrar a hospitalidade do meio de hospedagem (enquanto arquitetura) não só como condição espacial interna à edificação. Para tanto, o método interpretativo de avaliação dos resultados esteve amparado pelas teorias de hospitalidade urbana, essencialmente com o trabalho de Lucio Grinover (2007), que se ampara em teorias de urbanização acerca de imagem e paisagem urbanas, sobretudo nos trabalhos de Kevin Lynch (2010).

\section{FUNDAMENTAÇÃO TEÓRICA}

\subsection{Hospitalidade em meios de hospeda- gem}

Pode-se justificar e fundamentar a hospitalidade por aspectos físicos do espaço em meios de hospedagem. Sendo assim, veem-se autores que se utilizam do mote da estética de um hotel enquanto aparência física do produto hoteleiro, o que se pode "sentir" com ela, as qualidades sonoras dos ambientes hoteleiros, dos sabores na oferta de restauração e até o cheiro dos ambientes, como signos vinculados à hospitalidade (Garvin, 1992).

Nesse sentido também, a hospitalidade do espaço de um meio de hospedagem pode ser explicada através da psicologia com os conteúdos de "experiência" ou de "transferência" mental. No caso "experiencial", afirmações de Yu-Fu-Tuan (2013) podem explanar as diferenças entre as categorias de espaço e lugar (atribuídas na análise 
dos edifícios hoteleiros, por exemplo): os diversos espaços de um hotel podem constituir a ideia de lugar memorável (também para cidadãos locais e não somente hóspedes) porque se correlacionam com códigos e signos sociais de marcação de "lembranças" na vida; assim, a experiência do espaço arquitetural do ballroom de um hotel pode ser o fator para a recordação de uma festa de batismo, de uma festa de aniversário, casamentos, bodas, etc. Um exemplo de "transferência" mental é o fato de um hóspede, ao entrar em seu quarto de hotel, poder se emocionar pela identificação da decoração ou mobiliário de situações passadas (de ambientes semelhantes que ele já vivenciou) (Tricárico \& Vargas, 2017).

De sorte que é possível associar o valor semântico e sensorial do espaço com a hospitalidade: "O exercício da hospitalidade é uma retomada do simbólico" (Gotman, 2001).

Pode-se também interpretar através do uso da língua a devida relação entre o meio de hospedagem e a hospitalidade. Nos países de língua latina houve a opção pelo uso do termo "hotelaria" ao se referir a meio de hospedagem; mas este mesmo significado para "hotelaria" surge em países anglo-saxônicos como hospitalidade (Camargo, 2015). Daí, portanto, o uso de hospitality para designar "hotelaria" e não o uso de hotelbusiness (Camargo, 2015). Grinover (2007) assinala que o Oxford English Dictionary registra o significado de hospitalidade como a "recepção e o entretenimento de hóspedes, visitantes, estrangeiros" e é oriunda do termo "hospício", casa de repouso como restauração para os peregrinos da Idade Média. Portanto, há uma clara associ- ação entre espaço edificado (casa de repouso) e hospitalidade, bem como a ideia de "entretenimento de hóspedes" conferindo o caráter "emotivo" que as atividades e os espaços deveriam oferecer na recepção dos hóspedes.

Para Gotman (2010), o termo hospitalidade está carregado de diversos significados, tendo surgido no vocabulário francês em 1206, significando, sobretudo, “alojamento gratuito de caridade aos indigentes", vinculando-se a caridade como virtude teológica cristã; já no século XVI, hospitalidade retoma o significado "inspirado" na Antiguidade, segundo Antoine Furetière em seu Dicionário Universal de 1684: há uma hospitalidade fundamentada na caridade, na oferta de abrigo e na benevolência para com os indigentes; e há outra hospitalidade se referindo ao direito recíproco de proteção entre pares.

Camargo (2015) afirma que certo desprestígio e preconceito (inclusive por parte da academia) "ronda" o ideal de hospitalidade, efetivamente quando se referida à hotelaria contemporânea. Como interpretação de hospitalidade, pode-se incluir a cobrança por diárias e a constatação do lucro oriundo dos serviços hoteleiros. Até mesmo o meio acadêmico se voltou para a formação de profissionais com o perfil para o mercado de negócios hoteleiros, "ofuscando" uma concepção humanista para o tema da hospitalidade (Camargo, 2015). Ou seja, a concepção da hospitalidade muito se configurou em razão dos serviços da empresa hoteleira; onde até mesmo o espaço do hotel era essencialmente tratado como fator de gestão do empreendimento e dos negócios. 
De sorte então que seria necessário percorrer uma história dos meios de hospedagem para demonstrar que a evocação do espaço em meios de hospedagem se expressa através da hospitalidade não necessariamente empresarial.

Nesse sentido, Camargo (2015) evidenciou a possibilidade da associação entre hospitalidade e estética (diga-se do espaço inclusive): "Uma associação de estética e hospitalidade poderia encontrar na 'finalidade sem fim' de Kant (1994) uma boa pista de pesquisa. O mesmo Kant poderia introduzir o estudo da ludicidade, do prazer associado à ação humana de receber pessoas (...)" (Camargo, 2015).

Obviamente que as proposições de "ludicidade" e "ação humana de receber pessoas", (conforme citação acima) podem prescindir de suportes espaciais.

De outra maneira, cabe a observação de Rita de Cássia Ariza da Cruz (2002) ao afirmar que a hospitalidade é o ato de acoIhimento que proporciona bem-estar ao hóspede; e, portanto, ainda que se tenha o ingrediente do pagamento por esse serviço de restauração, não são excludentes os conteúdos de hospitalidade. Cruz (2002) propõe que mesmo não sendo paga, muitas vezes a hospitalidade está sendo oferecida de forma não aceitável e não espontânea por parte do anfitrião; portanto, o fato de não se pagar por uma pretensa hospitalidade, não quer dizer (necessariamente) que ela se efetivou.

Ainda que não cobrada, a hospitalidade oferecida pelo anfitrião muitas vezes podia ser por uma obrigação dos códigos e condutas religiosos de então: o medo do "castigo" dos deuses para os maus anfitriões parece ter sido uma "moeda de troca" para que o hospedeiro assim a fizesse de forma pretensamente "voluntária". De modo que se pode discernir entre uma hospitalidade "preparada", "treinada" e "planejada" (digase do espaço hoteleiro inclusive) e uma hospitalidade voluntária por parte do anfitrião: "Ser anfitrião não significa ser hospitaleiro" (Wada, 2003).

Atualmente, muitas empresas do setor hoteleiro não só comercializam seu produto "hotel", mas vendem "experiências" (através do espaço, inclusive) como signo de hospitalidade - condição desta fase do capital, explicada por Pine e Guilmore (1999) como uma quarta atividade econômica (depois dos setores primário, secundário e terciário), diferenciando-se dos bens e serviços, porque agrega valores evocativos até então não identificáveis (Rubino, 2009).

Parece ser inexorável que qualquer relação interpessoal direta com o hóspede em algum momento deve incluir a condição de uma hospitalidade genuína, mesmo se tratando (em princípio) de uma hospitalidade comercial (Lashley, 2004): o valet do hotel pode ajudar um idoso a atravessar a rua, a relação entre um recepcionista e o hóspede pode incluir trocas culturais e de informação que não estavam "previstas" como cobrança da diária do hotel.

E se pode pensar ainda que dentro de uma interpretação de uma hospitalidade comercial, a satisfação do hóspede se daria o quão mais "luxuoso" e "caro" são os serviços de hospedagem; porém, muitos depoimentos têm demonstrado que uma excelente experiência em hotel também se dá em unidades mais simples e baratas, porém aconchegantes e dotadas de conforto (como atributos espaciais) (Lockwood \& Jones, 
2002).

O fato é que as duas categorias de hospitalidade - tanto voluntária como empresarial - podem por vezes se fundir. Parece ser difícil uma distinção definitiva acerca desse tema. Petrocchi (2002), referindo-se à hotelaria, afirma que mesmo como negócio, ela deve preliminarmente satisfazer o cliente e não ser entendida como venda de serviços e produtos: "Isso é customização. Em suma, vive-se a era do cliente" (Petrocchi, 2002, p. 77). Petrocchi (2002) procura justificar esta condição da personalização do cliente através de uma visão empresarial através de um "quarto" tipo de oferta econômica - "pós-serviços" - que deve atingir a sensibilidade do cliente - e eis o suporte espacial para tanto.

\subsection{A hospitalidade em meios de hospeda-} gem essencialmente associada a espaços e serviços internos à edificação

Convém, portanto, para o objetivo dessa pesquisa, evidenciar a hospitalidade durante o percurso da história dos meios de hospedagem, demonstrando que ele ofereceu condições sensorial e semântica, mas, essencialmente do espaço interno às edificações para alojamento ou hoteleiras.

São poucos registros que sinalizam o início da história dos meios de hospedagem, porém, sabe-se que eles surgiram pela necessidade de viajantes por um abrigo, apoio e alimento em suas viagens (Campos \& Gonçalves, 1998). Antes da Antiguidade Clássica havia referência à hospitalidade em tavernas: o Código de Hamurabi (cerca de 1700 a.C.) anunciava esses locais como "casas de prazer". Encontravam-se na Antiga Pérsia tendas construídas para paragens de caravanas nos chamados khans (espaço com estábulo, pouso e fortaleza) (Walker, 2002, p. 4).

Desde o século VI a.C. já havia demanda por hospedagem em razão do intercâmbio comercial entre cidades mediterrâneas. Naquele momento, o meio de hospedagem se caracterizava pelo auto-serviço, eram partes de residências ou quartos ocupados com três até dez camas, sem a diferenciação do tipo de hóspede (Duarte, 1996).

A Antiguidade será marcada pela hospitalidade em instâncias hidrominerais na Britânia (Inglaterra), na Helvécia (Suíça) e no Oriente Médio (Andrade, Brito, \& Jorge, 2000, p. 19).

Os jogos olímpicos eram realizados no santuário de Olímpia, na Antiga Grécia; ali então foram construídos balneários e uma hospedaria. Os balneários de águas termais não constituíam necessariamente uma hospedagem, mas eram lugares de lazer que dispunham cômodos para descanso (Campos \& Gonçalves, 1998).

A noção de hospitalidade como acoIhida foi verificada na Grécia Antiga através dos códigos rituais de hospitalidade: oferecia-se ao hóspede um banho inicial para se refrescar; depois o colocava no lugar considerado o mais acolhedor da casa, sala ou quarto, onde se acendia uma lareira, símbolo do deus Lares (daí a etimologia de "lar"); derramar perfume na cabeça dos viajantes mais importantes era um sinal de boasvindas (Dias, 2002, p. 100); o anfitrião ainda cuidava dos pés do viajante sem lhe perguntar o nome ou a razão de sua viagem, mantendo certa "distância" em relação ao "es- 
trangeiro", em respeito à sua identidade, origem e singularidade (Grinover, 2007, p. 35).

No período Clássico Greco-Romano houve o aumento das trocas de alimentos e utensílios, fazendo com que as viagens também precisassem de locais para descanso e restauração, que se deram primeiramente nas casas dos próprios habitantes. Mas, com o passar do tempo, a hospitalidade na Grécia e Roma também pôde se verificar espacialmente em tavernas - as tabernae. Marco Polo concluiu que muitas tavernas estavam "à altura de um rei". O florescimento do Império Romano fez tavernas e estalagens locais para encontros de mercadores, estudiosos e atores, sendo assim chamadas por divertorium. Tavernas e estalagens junto às estradas eram locais para pessoas da mais "baixa espécie" (prostitutas, bêbados e viciados, pessoas de hábitos rudes e moral duvidosa), chamados por ganea (Dias, 1990, p. 28).

No Império Romano também se verifica o stabulum como hospedagem de viajante e tratamento da montaria; possuía um tipo de hóspede diferenciado (por ter cavalos como meio de transporte). A mutatione era construída em vias mantidas pelo Estado Romano, dava suporte à troca de animais em trânsito e para o descanso do viajante. A mansione era destinada a abrigar tropas militares. A popinae ofertava comida e bebida; a oenopolia ofertava bebidas alcóolicas e a thermopolia ofertava bebidas quentes (Dias, 1990, p. 28).

O hostellum no Império Romano era um palacete onde reis e nobres se hospedavam em viagem (Duarte, 1996).

As residências de hospedagem dos romanos demonstravam espacialmente recursos materiais próprios à hospitalidade no cotidiano, bem como àqueles recursos necessários para suprir as carências de um viajante (Dias, 2002, p. 103). No período do Império Romano, os apóstolos de Jesus Cristo pregavam o ideal de uma casa cristã com o dever de um "albergue de Cristo" (referenciando-se a caridade cristã como moral para se ofertar um meio de hospedagem) (Grinover, 2007, p. 35).

Com a decadência do Império Romano, a hospitalidade pública se tornou um pressuposto das ordens religiosas (Walker, 2002 , p. 5). As tavernas, tidas como locais do "prazer" e como espaço mundano, não podiam mais receber peregrinos religiosos; eles se hospedavam em pousadas junto aos templos e lugares sagrados. O Cristianismo e as Cruzadas, nesse sentido, contribuíram para o incremento dos meios de hospedagem (Monteiro, 2005). Carlos Magno no século VIII construiu pousos para peregrinos religiosos por toda Europa, promovendo-se também segurança e pouso para ordens de cavalaria. Corporações medievais "abriam suas casas" para o devido acolhimento, assemelhando-se com aposentos de mosteiros (Walker, 2002, p. 6).

Hospitais e albergarias eram hospedarias para peregrinos nos lugares "santos", muitas vezes localizados junto aos mosteiros, ofereciam tratamento médico (daí o "hospital" como se conhece atualmente) e floresceram no século $\mathrm{XI}$, sobretudo em Portugal. No período medieval também se nota o surgimento das estalagens ou estáus (ou estáos, ou hostáos) como casas de aposentadoria pública ou da corte (Dias, 1990, p. 29). No século XIII, na Europa, o hospitalis 
era lugar de caridade para com indigentes e viajantes; também promovia conhecimento mútuo entre os internados (Grinover, 2007, p. 36).

Em Paris, no século XIII, a prestação de serviços de hospitalidade era regulamentada; portanto, tida como atividade consolidada e crescente (Dias, 2002, p. 103). Por toda Idade Média, o acolhimento a viajantes foi tratado como obrigação espiritual e moral (Andrade et al., 2000, p. 18). Ainda durante a Idade Média e já nos primórdios da era moderna, a hospedagem se consolidou em abadias, mosteiros, acomodações junto a correios, abrigos para peregrinos religiosos e cruzados (Andrade et al., 2000, p. 19). Florença, por exemplo, em 1282, criou a junta de empresários de alojamentos, com o intuito de defender os interesses comuns daqueles empresários (Pires, 1991a).

O termo hospitalidade também derivou do termo hospice, e que atualmente possui significado ligado aos espaços de "asilos" ou "albergues"; termo oriundo de uma palavra francesa que significa "dar ajuda ou dar abrigo aos viajantes". Um dos hospices que ficou mais conhecido é do Beaune, na Borgonha, França, inaugurado em 1443 (Walker, 2002, p. 4). Aspectos espaciais relevantes do Hospice de Beune são assim relatados: "A extravagância do Hospice de Beaune é desconcertante, com ornatos arabescos, pátios rodeados de frontões e uma deslumbrante cobertura de telhas policromadas (...). O Hospice é ainda valorizado por notável coleção de arte (...) tais como o Juízo Final, de Roier van der Weyden (...)" (Walker, 2002, p. 4).

No século XVI, durante a Dinastia Tudor na Inglaterra, houve um aumento no número de estabelecimentos de hospedagem em razão da estabilidade política (Chon, 2003, p. 87). Associa-se o fato de que as carruagens se tornaram o meio de transporte mais utilizado na Inglaterra, eram necessárias as paradas em pousadas e tavernas (post houses, estalagens de correios, hotéis de carruagem ou stagecoach inn) para a devida restauração (Walker, 2002, p. $6)$.

De maneira geral, a era das grandes monarquias nacionais ficou marcada por hospedagem aos nobres, operacionalizada pelos Impérios em palácios, em instalações militares e administrativas. Viajantes plebeus eram acolhidos precariamente em albergues e estalagens (Walker, 2002, p. 6).

Também no início da colonização do Novo Mundo se pode notar a implantação de meios de hospedagem: em 1642 os holandeses montaram a primeira taverna nos Estados Unidos, o Stadt Huys, em Niewn Amsterdam (atualmente Nova York). Em 1643, a Companhia das Índias Orientais fundou a Taverna Krieger, em Bowling Green (Walker, 2002, p. 10).

Os primeiros registros de hospitalidade na Terra de Santa Cruz (Brasil) foram de caráter religioso e familiar. "Casas de Hóspedes" aparecem em registros das antigas capitais do Brasil (como Salvador e Rio de Janeiro) nos séculos XVII e XVIII, estavam localizadas em conventos, em ordens religiosas que davam hospedagem a confrades em trânsito e muitas foram tidas como "hospícios" em seus primórdios (como, por exemplo, o Hospício da Ordem Terceira de Santo Agostinho, em Salvador, fundado em 1693); mas, com o tempo, esses locais se transformaram em hotéis a partir de poucas 
adaptações (Buarraj, 2004).

O século XVIII reifica a noção de hospitalidade com acepção comercial, ainda que carregue a prática da troca, da reciprocidade e da pacificação (Montadon, 2003, p. 138). Assim sendo, manifestam-se no século XVIII iniciativas para a efetivação de um hotel que fará a cobrança pelos serviços prestados; em 1760 a palavra "hotel", oriunda de hôtel-garni, passou a ser utilizada na Inglaterra; significava um estabelecimento conhecido em meio francês, mas se identificando no contexto inglês com acomodações luxuosas e ostentativas (Dias, 2002, p. 104). Em 1774, surgiu o primeiro hotel familiar em Londres, na casa de Lord Archer, em Convent Garden (Dias, 1990, p. 32).

Em 1788, foi inaugurado um dos primeiros hotéis europeus - o Hotel Henrique IV - em Nantes (Walker, 2002, p. 7).

No Brasil, em 1785, constituiu-se a Casa dos Hóspedes no Colégio da Companhia de Jesus, em Salvador; o qual hospedou personalidades, pois a participação da Igreja Católica tinha papel fundamental na hospedagem de visitantes ilustres para aquele momento (Duarte, 1996).

A idéia de resort hotel apareceu no final do século XVIII e início do XIX (Dias, 2002, p. 104). Também nesse período, surge o grand american hotel nos Estados Unidos, onde qualquer cidadão ou turista poderia usufruir os serviços oferecidos (desde que pagasse por eles); diferente da hotelaria européia que ficou "fechada" à sociedade como um todo, servindo somente à aristocracia.

Ainda no século XVIII, houve um rápido crescimento da hotelaria devido ao pioneirismo dos "innkeepers" nos Estados
Unidos, concomitante com uma política de igualdade própria da democracia norteamericana (Duarte, 1996). Dessa maneira, no ano de 1794 em Nova York, o primeiro prédio projetado para ser um hotel foi considerado um "imenso estabelecimento", pois $70 \%$ da área total era destinada ao uso social; a população da cidade, que era de 30 mil habitantes naquele momento, passou a utilizar o hotel para encontros sociais. Desde então, vários hotéis foram construídos como um lugar importante das cidades norteamericanas. Destaca-se, nesse viés, o primeiro "arranha-céu" que se construiu em Nova York - o edifício Adelphi Hotel - com seis andares.

A instalação da Família Real portuguesa no Rio de Janeiro, em 1808, promoveu hotéis de categoria, contando com novos serviços nunca antes conhecidos pela população da colônia brasileira (Pires, 1991a).

Data do início do século XIX inovações na hotelaria do México: em 1825 se constrói o primeiro hotel de luxo - o Hotel Itúrbide (Duarte, 1996).

No início do século XIX se introduziu o gerente de hotel, recepcionistas e a configuração de toda equipe hoteleira; portanto, surgem novas concepções espaciais para o edifício hoteleiro, dadas aos novos serviços prestados (Dias, 2002, p. 104).

$\mathrm{O}$ arquiteto Isaiah Rogers (considerado autoridade na construção hoteleira), projetou em 1829 o chamado "Adão e Eva da Hotelaria", pelo fato de ser o maior e mais caro hotel devido às principais inovações físicas, com acomodações privadas, quartos single e double (pois até então os hotéis possuíam grandes quartos com mui- 
tas camas); as unidades tinham portas com fechaduras; cada unidade possuía bacia e jarro para higienização pessoal (o hotel oferecia um sabonete de brinde) e disponibilizava um mensageiro para localizar hóspedes dentro do hotel. Tais inovações foram copiadas em várias cidades norte-americanas, pois todas queriam um hotel luxuoso (Duarte, 1996).

Em meados do século XIX, albergues rurais surgiram como possibilidade de escapismo (como mote do "retorno ao campo") de um meio urbano tumultuado, marcado por multidões empolgadas pela Revolução Industrial nas cidades (Duarte, 1996).

Na segunda metade do século XIX, Cesar Ritz, através de sua hotelaria, criou o termalismo italiano, transformando a pequena vila de Salsomaggiore em um destino termal de importância mundial (Dias, 1990, p. 40).

Ritz conseguiu associar os espaços do hotel com experiências inusitadas: concertos musicais durante as refeições; diversões ao ar livre; decoração do hotel com flores naturais; propõe para o quarto de núpcias a iluminação indireta e a iluminação "peneirada", tornando a mulher mais sedutora; desenvolveu abajures para iluminar a comida sem ofuscar os integrantes à mesa (Dias, 2002, p. 115); introduziu armários embutidos nas unidades habitacionais (Dias, 1990, p. 40). Ritz colocou closets nas unidades habitacionais dos seus hotéis; propôs uma ante-sala em um nível mais baixo que o salão de jantar no Hotel Carlton de Londres, para que as mulheres entrassem e saíssem "teatralmente" pelas escadarias necessárias ao passar pelos diferentes níveis (Dias, 2002, p. 111). Ritz dotou poltronas das salas de jantar com ganchos para que as mulheres pendurassem suas bolsas. Para Ritz, roupas de cama deveriam ser leves para melhor lavação e colchões deveriam ter capa protetora (Dias, 2002, p. 114). Pode-se ainda verificar que Ritz incluiu um banheiro privativo dentro do quarto de hotel (Andrade et al., 2000, p. 18).

Ritz tinha no lidar com pessoas a maior virtude para a profissão de um hoteleiro (Walker, 2002, p. 21); e a fez (inclusive) revertendo esse pensamento para o valor do espaço interior do hotel como hospitalidade. Cesar Ritz não só teve sucesso como empresário hoteleiro pelo "planejamento" da hospitalidade, mas porque sua ação planejadora esteve também amparada por uma hospitalidade voluntária, um valor predecessor como "sensibilidade" hospitaleira. O termo "ritz" (oriundo de Cesar Ritz) foi incluído no vocabulário inglês e significa requinte, luxo, conforto, elegância e prestação de serviços de alta qualidade de um hotel (Dias, 2002, p. 105). Cesar Ritz tratava muito bem seus clientes, recordando-se em detalhes de suas idiossincrasias, do que eles gostavam e do que eles não gostavam (Dias, 2002, p. 114).

Petrocchi (2002) aponta que o credo do empreendedorismo de Ritz, "simbolizado" (sobretudo) no Ritz-Carlton, é que "A estada no Ritz-Carlton aguça os sentidos, infunde bem-estar e satisfaz até mesmo os desejos e as necessidades não manifestados de nossos hóspedes." Cabe então se perguntar se as atitudes de Ritz eram somente voltadas para a obtenção do lucro na cobrança de diárias e pelos serviços prestados de restauração, ou se em nenhum momento sua "inventividade" para negócios hoteleiros 
esteve motivada por sentimentos de hospitalidade genuinamente voluntários. Ritz criou signos para hotelaria que se perduram na hotelaria contemporânea.

Em meados do século XX, após a Segunda Grande Guerra, o contexto econômico norte-americano se encontrava em grande desenvolvimento, também porque a Europa ficou arrasada com a guerra. "Cidadãos médios" norte-americanos tinham poder de compra do automóvel; e, em gozo de suas férias trabalhistas, viajavam com toda a família pelo território norte-americano. Diante da necessidade de paradas e pernoites pelo caminho rodoviário, aparecem os motéis, alterando-se condições dos hotéis tradicionais: o turista de automóvel escolhe estradas com valores cênicos (parkways), as quais serão privilegiadas na implantação de motéis (Motels, Hotels, Restaurants and Bars, 1960). Nota-se ainda que o modelo de motel norte-americano eliminou a "espera" nos lobbies, excluiu a "formalidade" do serviço de recepção, acabou com problemas do estacionamento (pois o carro ficava junto à unidade habitacional, conferindo conforto e tranquilidade), acabou com gorjetas (pois hóspede ficava independente dos serviços oferecidos), os quartos eram novos e com televisão em cores, havia piscina privativa (Dias, 1990, p. 37).

Nos anos 1960 surgiu Robert Huyot e sua hotelaria para "homens de negócios". Hyot enfatizou a sobriedade nos ambientes do hotel, concomitante com o perfil daqueles clientes. Huyot expôs que o hotel para homens de negócios tem que ser "diplomático", econômico e se adequar aos valores estéticos, psicológicos e emocionais da clientela (Dias, 1990, p. 42). No entanto, mui- tos hotéis para os "homens de negócios" ofereceram áreas de convivência ao ar livre, algo pouco usual em hotéis corporativos (Otto, 2011, p. 3).

Nos anos de 1970 apareceram os Days Inn, Super 8 Motels e Comfort Inns e algumas corporações hoteleiras, tais como Marriott, Four Seassons, Hyatt, Canadian Pacific, Sheraton, Radisson, Hilton, Ramada, que se expandiram por todo mundo (Walker, 2002, p. 20).

Há uma personificação na hotelaria dos anos 80 do século XX; surgem hotéis de arte, hotéis design, hotéis boutique; e, exemplarmente, algumas pousadas em Portugal que incluíram a experiência da culinária e da gastronomia locais junto à experiência da estada (Oliveira, 2006, p. 62).

Nos anos 1980, estâncias turísticas em lugares tidos como "exóticos" se tornaram populares e acessíveis. Os anos de 1990 foram marcados por recessões nas economias nacionais e por momentos de guerras que diminuíram receitas do turismo; e, por conseguinte, a hotelaria organizou associações e parcerias no intuito de se manter ou até se consolidar (Walker, 2002, p. 20).

Contemporaneamente, dos anos 2000 até hoje, vive-se um "novo" turismo, muitas vezes classificado como pósmassificado e com valores afeitos à solidariedade e afetividade (turismo cultural e de base comunitária, por exemplos); onde o turista, em sua busca por experiências pessoais, associa valores votivos do "coração" (Petrocchi, 2002, p. 78). Nesse viés, a atual hotelaria (enquanto parte da cadeia produtiva turística) passa a construir um vínculo com o desenho, cultura material e simbólica do lugar (do espaço, portanto) (Montaner, 
1997).

A "aparência física" dos espaços de um hotel geralmente é "lembrada" como imagem memorável. Imagens memoráveis do "produto" hotel demonstraram interferência na tomada de decisão quando se fazem as reservas de quartos (unidades habitacionais) (Chen, Ekinci, Riley, Yoon, \& Tjeiflaat, 2001). De outra maneira, pesquisas sobre qualidade da hospedagem também inferiram que o ambiente interno tanto como o ambiente externo de um hotel, deve ser bem cuidado, limpo e iluminado (Ladhari, 2012). Assim, por exemplo, pesquisas realizadas no Hotel Hamilton na Nova Zelândia demonstraram o papel relevante atribuído pelo hóspede à aparência e ao conforto do quarto de hotel (unidade habitacional), referindo-se também à qualidade da mobília nele existente (Mohsin, 2007).

Referências locais, muitas vezes com recorrência aos valores do lar, podem ter outros objetivos além do ideal do home away from home ${ }^{6}$ na hotelaria contemporânea; pois pesquisas realizadas na China sugeriram que uma hotelaria de escala doméstica pode contribuir com o setor hoteleiro chinês (de grande escala) a superar dificuldades oriundas desde o final da década de 1990; haja vista que em mercados com alojamentos saturados, pequenos hotéis garantiram o ciclo econômico (em escala nacional chinesa) (Gu, 2003).

Trabalhos recentes têm demonstrado o valor que a arquitetura hoteleira tem depositado na inserção de sustentabilidade,

\footnotetext{
${ }^{6}$ Quanto ao conceito de home away from home, ver o trabalho de Célia Maria de Moraes Dias (1990), elencado no final do artigo como referência bibliográfica.
}

automação e conteúdos semânticos "emotivos" nos espaços interiores de um hotel, dando subsídios para outras manifestações da arquitetura (Tricárico \& Vargas, 2017; Tricárico, Rossini, \& Tomelin, 2016; Tricárico, 2016; Oliveira, Tricárico, Velasquez, \& Gorski, 2015; Tricárico, Rossini, \& Tomelin, 2016a; Tricárico, Rossini, \& Tomelin, 2015; Tricárico, 2015; Tricárico, Tomelin, \& Rossini, 2014; Tricárico, Oliveira, Rossini, \& Miranda, 2013).

Nota-se, portanto, que a abordagem bibliográfica acerca da hospitalidade (seja voluntária ou empresarial) do espaço em meios de hospedagem se caracteriza efetivamente pela descrição da mesma em espaços interiores à edificação, da prestação dos serviços e no máximo, da escala arquitetural do espaço hoteleiro. Não tendo, portanto, em nenhum momento da "varredura" bibliométria se verificada a relação hipotética desta pesquisa: meios de hospedagem como signo e atributo de hospitalidade urbana.

\section{RESULTADOS E DISCUSSÃO}

\subsection{A hospitalidade dos meios de hospeda- gem à escala urbana e da cidade}

Cabe observar que se pode outorgar aos meios de hospedagem a capacidade de hospitalidade também exposta para a cidade e na paisagem urbana, para além de sua condição sistematizada até então em espaços internos à arquitetura. Tal interpretação será possível porque muitos dos meios de hospedagem tratados a seguir conseguiram se configurar como referências e marco urbano, lugares da e na cidade.

Lantos (1977) propõe aos avós que 
nunca saíram de suas pequenas cidades ou de suas aldeias, que se fossem presenteados (juntamente com seus netos) para uma visita à "cidade grande", ganhando também a estada em um grande hotel; ficariam espantados na chegada diante do hotel; depois se espantariam também com o luxo e o conforto do edifício hoteleiro; denotando-se, portanto, que o hotel na cidade se diferencia das demais arquiteturas. De modo que Lantos (1977) observou que as catedrais ficaram "ridículas" perante edifícios hoteleiros.

Os edifícios hoteleiros também promoveram novos "ídolos" para nossas cidades: Rockefeller, Hilton e Meliá - dado o conteúdo simbólico dos hotéis na imagem e paisagem urbanas; marcando lugares urbanos. Até porque grandes hotéis são construídos em locais de referência e porções nobres dentro das cidades, assim como sedes de governo, igrejas, quartéis, bancos, entre outros (Buarraj, 2004).

Cesar Ritz, nos finais do século XIX, escolhia o local de seus hotéis próximos a uma praça central, tendo-se uma vizinhança requintada com perfumarias, joalherias e ateliês de alta costura (Dias, 2002, p. 113); ou seja, usos urbanos que "aguçavam" sentidos: olor das perfumarias ou o brilho das vitrinas, numa "animação" citadina da prática do footing de compras. Para Ritz, coisas "bonitas" do ambiente urbano, quando expostas, tornavam o caminho do hóspede mais prazeroso no retorno para o hotel, ou até quando se partia do hotel, guardando-se uma imagem urbana memorável (Dias, 2002, p. 119).

A adequada localização de um hotel na cidade se consolidou na "máxima" do hoteleiro Conrad Hilton. Para Hilton, há três condições primordiais para o sucesso de um hotel: em primeiro lugar é o local; em segundo lugar vem o local e em terceiro lugar se encontra o local (Dias, 2002, p. 113).

Cidades norte-americanas ficaram reconhecidas mundo afora, sem contar ainda com o teor identitário para seus cidadãos, da imagem urbana que palace-hotéis construíram ao longo do tempo. Assim, como exemplo, deu-se em Chicago através do Hotel Palmer House; ou em Nova Orleans com os hotéis Saint Charles e Saint Louis; em Saint Louis com o Planter's Hotel; com o Hotel del Coronado em San Diego (sendo também um referencial histórico). Outras cidades norte-americanas, como Washington e Buffalo, contaram com a extravagância e opulência da edificação hoteleira como um símbolo de cidade (Walker, 2002, 14).

Deve-se verificar também que os grandes hotéis norte-americanos representaram um característico "amor" estadunidense pela grandeza; segundo Donzel (1989), os hotéis constituem um dos únicos lugares em que a sociedade norteamericana se sente segura em ter uma vida pública, com "urbanidade", e em conviver com experiências civilizatórias na esfera "pública"; sem dúvida que são espaços "privados" somente do ponto de vista legal (Donzel, 1989, p. 8).

Deve-se notar que a monumentalidade do grande hotel norte-americano veio acompanhada pelas revoluções das técnicas construtivas daquele momento, devidamente apropriadas pela arquitetura hoteleira - o arranha-céu e o elevador para subir tantos pavimentos - promovendo-se uma fruição visual "assustadora" do skyline de Manhattan para turistas que chegam pelo mar ou a 
partir das pontes que ligam o continente à ilha (Donzel, 1989, p. 11).

Entre arranha-céus nova-iorquinos, a cúpula rosa do Hotel Royal Hawaiian reluzia como uma "jóia" no azulado céu, considerada como um dos últimos "bastiões" da eloquente fantasia exótica norte-americana (Donzel, 1989, p. 185).

A visibilidade adquirida pelo grande hotel norte-americano também se explica por ele ter incrementado serviços urbanos: o Hotel Fairmont em Yosemite Valley, Califórnia, EUA, introduziu em 1939 um lounge bar no vigésimo andar do edifício, disponibilizando uma vista panorâmica e inusitada da cidade (Donzel, 1989, p. 35).

O valor simbólico na cidade do grande hotel norte-americano também pode ser expresso através de filmes premiados pelo Oscar; porque cineastas hollywoodianos identificaram a "grandiosidade" daqueles hotéis, que representados na cinematografia, criaram um signo identitário para muitos norte-americanos (Donzel, 1989, p. 37).

Nesse sentido também, verificam-se hotéis da Disney, sobretudo aqueles projetados por Michel Graves, com fachadas construídas com elementos jocosos, proporcionando alegria e descontração ao hóspede transeunte pela rua.

A relação que um hotel deve ter com a rua pode denotar a condição de hospitalidade urbana: o lobby do hotel pode oportunizar um acesso por uma rua pública, ao mesmo tempo em que pode garantir a circulação dos hóspedes dentro do hotel (Andrade et al., 2000, p. 125). Ambientes de uso coletivo para socialização apareceram contemporaneamente em hotéis design, integrando hóspedes, hotel e a cidade (Otto, 2011, p. 3).

Tricárico e Gastaldi (2015) demonstraram que ao longo da praia de Copacabana no Rio de Janeiro, Brasil, a presença dos hotéis é que pode garantir a referência de lugares ao longo de uma enseada e orla marítima essencialmente e "constantemente" marcada pela visão do horizonte da "linha" de mar e da areia da praia.

O caráter monumental da edificação hoteleira diante de outras arquiteturas na cidade se faz por formas arquitetônicas inusitadas elaboradas por arquitetos de "grife" ou até mesmo vinculadas às "grifes", tais como Bulgari, Armani e Camper; e a oferta dos serviços não é apenas para turistas viajantes, mas para cidadãos locais (Spolon, 2011, p. 175). Dentro dessa lógica da hotelaria contemporânea, pode-se elencar o Sofitel So Bangkok, "assinado" por Christian Lacroix, ou o Sofitel So Mauritius, "assinado" por Kenzo (Revista O Globo, 2013, p. 66).

Dentro da paisagem urbana brasileira, o motel adquiriu uma acepção de tipologia identitária que acabou configurando um "ícone" característico na paisagem urbana, jocoso por vezes na imagem da cidade, mas que "anima" o ambiente urbano:

O estilo desses motéis apresenta uma gama igualmente variada de opções. Encontramos réplicas de castelos medievais, construções egípcias e mesopotâmicas, prédios com estrutura moderna pintados em cores berrantes ou revestidos de materiais 'luxuosos' como mármore, granito, etc, presença de pinturas murais com alusões 'eróticas' ou com pequenos chalés separados uns dos outros compondo certa paisagem bucólica (...). Outro elemento que reforçaria o 'apelo sexual' seria o logotipo ou 'marca' do estabelecimento: maçã mordida, gatinha, sereia, etc." (Cavalcanti \& Guimaraens, 1982, p. 64) 
Muitos motéis brasileiros já estão optando por implantações e tipologias que verticalizam a unidade habitacional, deixando o térreo para o estacionamento do automóvel e o nível superior como unidade habitacional. Essa lógica na escolha da tipologia também tornou possível a abertura de vistas para o exterior sem tirar a privacidade dos ocupantes; assim alguns motéis cariocas podem utilizar a vista a partir da unidade habitacional para divulgar seu empreendimento: "vista panorâmica para as monta- nhas da Barra" e "vista para as montanhas e Pedra da Gávea" (Cavalcanti \& Guimaraens, 1982, p. 89).

Hotéis podem representar uma nação (Figura 1); também podem representar uma cidade, tais como o Grande Hotel Petrópolis em Petrópolis, RJ; o Hotel Palace Casino em Poços de Caldas, MG; o Hotel Renar em Friburgo, SC; o Palace Hotel de Caxambu, MG; o Hotel Copacabana Palace no Rio e Janeiro, RJ (Figura 2) (Tricárico \& Gastaldi, 2015).

Figura 1 - Imagem do Hotel Burj Al-Arab como propaganda turística dos Emirados Árabes Unidos

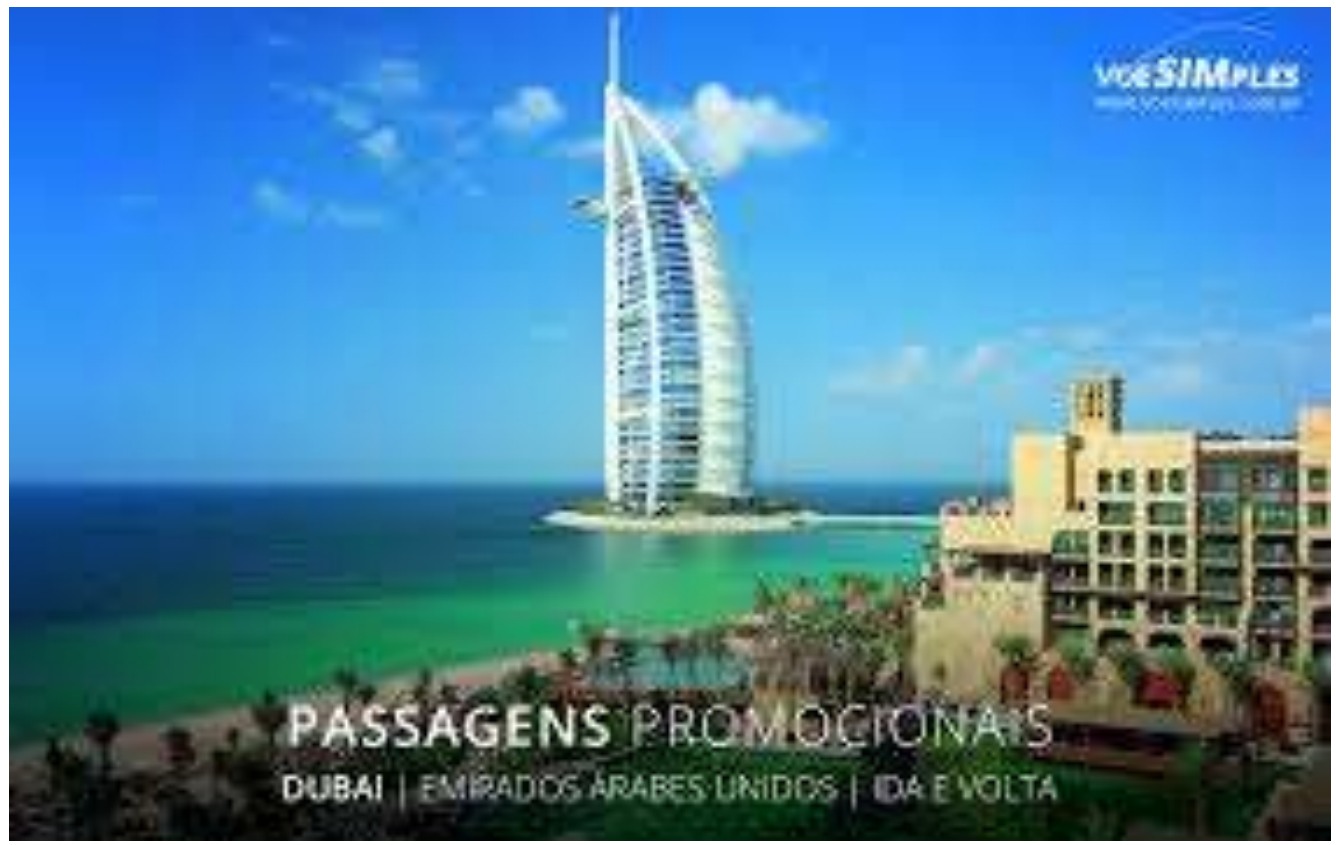

Fonte: http://www.fatimanews.com.br/turismo/predio-simbolo-de-dubai-e-o-unico-hotel-7-estrelasdo-mundo-veja/164004/ 
Figura 2 - Cartão-postal da cidade do Rio de Janeiro tendo como imagens o Hotel Copacabana Palace

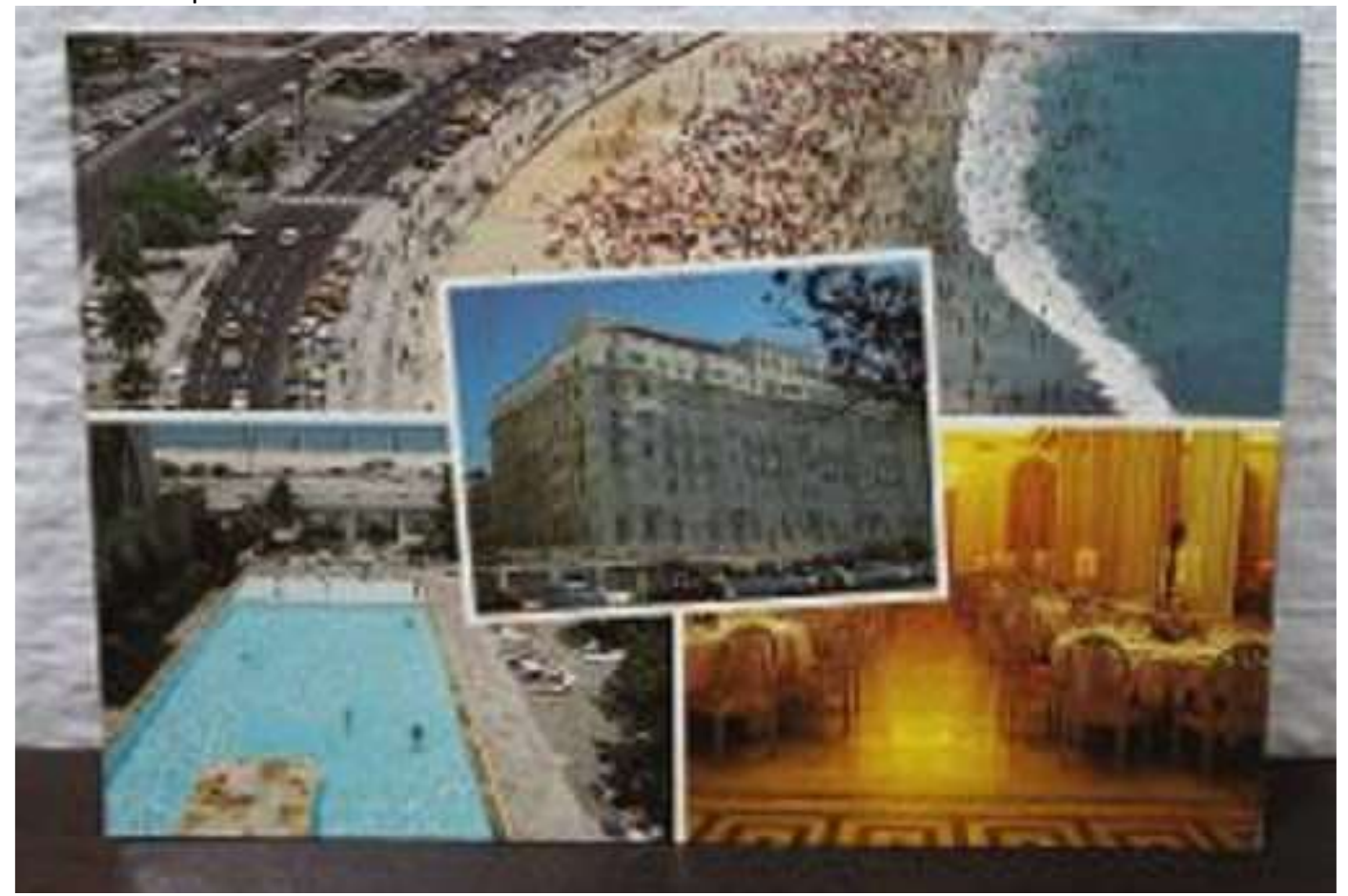

Fonte: http://colecoes.mercadolivre.com.br/postal-do-rio-de-janeiro,-anos-60,-copacabana-*g-f-b-144

De sorte que os exemplos elencados acima configuram referências imagéticas enquanto arquiteturas no espaço urbano (marcos urbanos), atributos de forma e significado verificados na imagem da cidade. Para McNeil (2008) os hotéis têm sido cada vez mais elementos estruturantes do espaço urbano, tanto como marco referencial, tanto como elementos de estratégias de reestruturação urbana.

Grinover (2006) se apóia no trabalho de Lynch (2010) para explicar que o espaço citadino pode estar carregado de hospitalidade: "Esses conceitos desenvolvidos por Kevin Lynch (1996), nos permitem resgatar essas análises, ainda atuais. Kevin Lynch considerava legível uma cidade ou um território quando os bairros, marcos ou caminhos pudessem ser facilmente reconhecíveis
(...)" (Grinover, 2006, p. 42; grifo dos autores).

Constitui-se um marco urbano para Kevin Lynch: “(...) ponto de referência, porém, neste caso são externos (...). Geralmente, elementos construídos, edifícios excepcionais (...) todos dotados de uma forma particular que facilita sua identificação. Podem estar dentro da cidade ou próximo a ela, a uma distância que simboliza uma direção constante (...)" (César, Tronca, \& Mattana, 2017).

Nesse viés, os meios de hospedagem estimulam a percepção do meio urbano, são condicionantes para uma cidade mais hospitaleira (Grinover, 2003, p. 35):

(...) a cidade torna-se mais hospitaleira na medida em que o usuário a "lê" com mais facilidade e seus elementos constitutivos 
são percebidos e interpretados sem grandes esforços (...) estudam-se os elementos marcantes da paisagem urbana, aqueles que apresentam individualidades, ou seja, traços de singularidade que, por sua vez, são pontos particulares, específicos da paisagem, que diferenciam e caracterizam o espaço urbano que está sendo estudado. Isso parece ser um ponto fundamental das características da hospitalidade, uma vez que ela vive, em parte, das especificidades dos lugares. (Grinover, 2003, p. 35)

Para Grinover (2007), a hospitalidade é um "dom" do espaço carregado pelos signos da acessibilidade, legibilidade e identidade (Grinover, 2007, p. 123) - portanto, aqueles atributos (também) já sistematizados por Kevin Lynch (2010) em teorias da urbanização.

Cabe verificar ainda que as categorias de análise identificadas por Lucio Grinover (2007) também estão afeitas com as teorias de hospitalidade de Raffestin (1997).

A representação de lugares através de um meio de hospedagem também pode se dar na escala de identidade de um bairro a partir da hotelaria. Para explanar e exemplificar tal condição, é recorrente o trabalho de Jane Jacobs (2003). Segundo Jacobs (2003), um território legível como bairro dentro de uma cidade deve incluir significativa porcentagem de edificações antigas de diferentes idades e estados de conservação variados. Áreas predominantemente com construções novas são pouco atrativas para a experiência identitária de lugares construídos ao longo do tempo; daí então que estas áreas não terão movimento de pessoas e consequentemente será pouco útil do ponto de vista de um comércio de rua, por exemplo.
O constante crescimento dos custos da construção é proporcional à demanda de edificações antigas, uma vez que prédios desvalorizados requerem uma renda menor que aqueles que ainda não saldaram o capital investido. Muitas das empresas que se tornaram lucrativas não teriam crescido se não houvessem encontrado um espaço de baixo custo em malhas urbanas "antigas" e consolidadas. Nesse contexto, as empresas de meios de hospedagem com baixo nível de investimento inicial, sobretudo as direcionadas ao público de menor renda (hostels e hotéis econômicos, por exemplos) podem encontrar em malhas urbanas consolidadas a infraestrutura adequada, ao mesmo tempo em que encontram em edifícios antigos um bom suporte para suas instalações.

Por isso, Jacobs (2003) sugere que o sucesso de um bairro está ligado com a diversidade de construções em estilos de época, bem como a ação do tempo sobre eles. O espaço urbano necessita de mesclas de prédios antigos para cultivar a diversidade (inclusive social) própria à cidade. Muitos dos prédios antigos, se bem distribuídos, tornam-se essenciais. Tal ideal de uma diversidade estética acumulada com edifícios ao longo do tempo vai ao encontro das proposições de Camargo (2015) acerca da condição de hospitalidade urbana, aliada a um processo que inexoravelmente inclui pessoas, numa condição para o "ver-e-ser-visto". Ora, se há pessoas, é porque também há uma oferta de serviços (inclusive de restauração aliados à hotelaria), denotando-se, por outro lado, a condição de hospitalidade urbana conferida por Latham (2003) e Bell (2007), ao entenderem a hospitalidade ur- 
bana a partir da comensalidade, dos serviços e comércio nos bairros.

A partir dessas considerações teóricas, pode-se elencar a hotelaria e os serviços de restauração - essencialmente de baixo custo para hóspedes - nos bairros de Palermo e San Telmo, Buenos Aires, Argentina são os hostels e até hotéis design (Figura 3) - que se "abrigam" em edifícios antigos - e por isso também se tornam um atrativo para um público específico que os procuram ou simplesmente percorrem aqueles bairros. Tal condição empírica também se fundamenta concomitantemente com as teorias de urbanização de Kevin Lynch (2010) (vinculadas com teorias de hospitalidade urbana de Lucio Grinover $(2003,2006,2007)$ ) acerca da imagem e paisagem urbanas: configurase a legibilidade dos bairros de Palermo e San Telmo pela possibilidade de um "agrupamento legível" do conjunto dos diversos hotéis que se apropriaram de edifícios antigos.

Também nos termos de Lynch (2010), interpreta-se que os hotéis ocasionam marcos no tecido urbano (referenciais de "lugares" identitários na e da cidade); por suas características peculiares: proporção e escala da edificação monumental em relação às outras edificações na cidade; detaIhes de cor, iluminação noturna e acabamentos "chamativos"; implantação da edifi- cação hoteleira junto à rua, criando-se acessos de sugestões de uso coletivo para ballrooms e restaurantes de hotéis.

O caráter identitário dos hotéis enquanto lugares da e na cidade vai ao encontro da noção de lugares de hospitalidade à escala urbana (Baptista, 2002, 2005, 2008; Salles, Bueno, \& Bastos, 2014; Stefanelli \& Bastos, 2016; Stefanelli, 2015).

Os edifícios antigos de Palermo e San Telmo não só passam então por um viés "patrimoniável" do bem esteticamente eleito, mas concentram parte afetiva do cotidiano (memória de antepassados, memória material do lugar, estilos arquitetônicas "aprazíveis" a diferentes gostos pela arquitetura), bem como possibilidade de desenvolvimento econômico (geração de emprego e renda para população local nos serviços de hotelaria e restauração). O confronto da população local (seja a prestadora direta de serviços, seja o cidadão transeunte ou morador do bairro) com o turista, expõe a proposição de hospitalidade urbana defendida por Severini (2014): relação social entre visitante e visitado, amparado pelos diversos espaços da cidade, sejam eles públicos ou até privados de uso coletivo (hotéis e restaurantes, por exemplos). 
Figura 3 - Sequência de imagens das entradas de meios de hospedagem em edifícios antigos em Palermo, Buenos Aires, Argentina
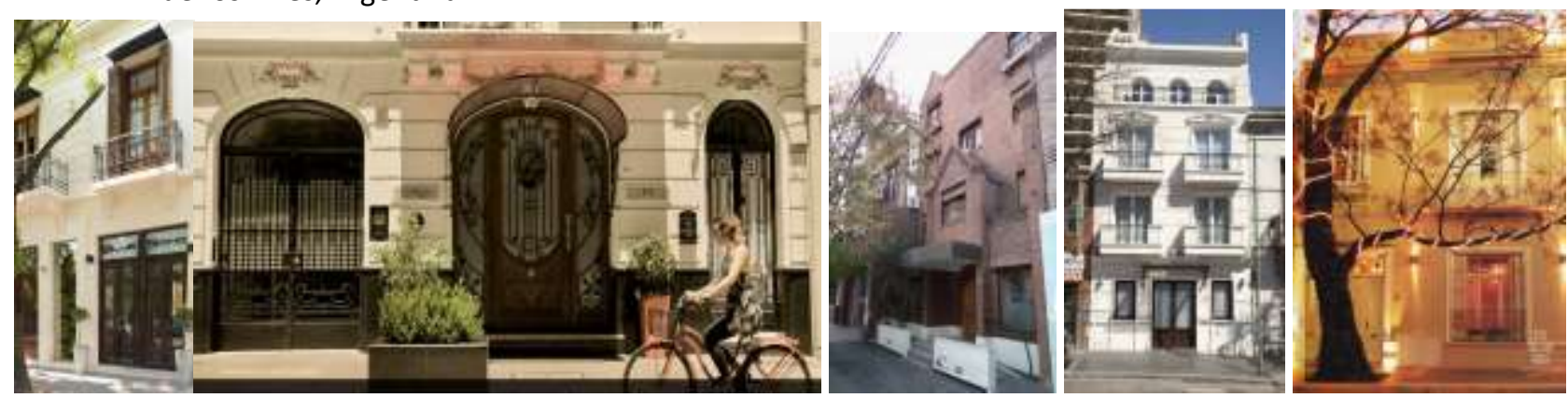

Fonte: da esquerda para a direita: http://www.hotelbluesoho.com/; http://www.duquehotel.com/; http://www.ninahotelbuenosaires.com/palermo-soho/; http://www.purobaires.com.ar/; http://www.malabiahouse.com.ar/docs/pt/malabia-house-hotel.php

A proposição de Severini (2014) vai ao encontro das teorias de Mauss (1974) que entende a hospitalidade urbana como um fato social "total", pois se "mistura" num suporte espacial diferenças sociais, inclusive contando com o outro estrangeiro (um possível turista, talvez). E que se adequam aos três " $D$ "s das categorias de Dumazadier (1980) para explicar a existência de hospitalidade urbana: descanso, diversão e desenvolvimento, minimizando as dificuldades cotidianas na cidade (Sagi, 2008).

Os estudos acerca da concepção do urbano a partir da imagem da cidade contribuíram concomitantemente com a noção de hospitalidade urbana e todo seu escopo ligado aos estudos em turismo; assim se pode verificar nos trabalhos dos pesquisadores latino-americanos como Roberto Boullón (2000) e Lucio Grinover (2006, 2007). Para eles, o "estrangeiro" se sente acolhido, bem recebido, sabe por onde tem de ir (legibilidade), encontra o que procura, passeia descompromissado se dedicando à contemplação sem o risco de se perder - porque existe uma imagem de cidade que cria uma informação legível acerca do espaço urbano e das arquiteturas que o compõe - tal oferta de informação é uma expressão de hospitalidade urbana: escolha de itinerários urbanos que vão além da rapidez do deslocamento, mas "também pelo fluxo 'emotivo' que se libera quando atravesso essas ruas" (Grinover, 2007, p. 146). Ora, essa condição é essencial para o turismo, uma vez que são pelas vias públicas que se dão os deslocamentos dos turistas nos destinos citadinos.

\section{CONSIDERAÇÕES FINAIS}

Constata-se que há a vinculação do termo hospitalidade com os meios de hospedagem e, especificamente, tratada em espaços de uso interno e serviços em hotéis; amparada por uma bibliografia específica; porém se pode inferir que há uma hospitalidade dos meios de hospedagem enquanto abrangência urbana, da cidade e da paisagem que até então uma bibliografia vascuIhada e atual ainda não inferiu. Ou seja, a hipótese dessa pesquisa se confirma, ao demonstrar, através dos conteúdos preconizados essencialmente por Grinover (2003, 2006, 2007), que os meios de hospedagem podem constituir um marco urbano (Lynch, 2010) e, como tal, são dotados de legibilida- 
de em meio urbano - atributo e signo de hospitalidade urbana.

A metodologia adotada, baseada em pesquisa de caráter exploratório e descritivo, foi conveniente nesse caso, pois é um primeiro momento de inferência acerca da hipótese levantada. Julga-se, portanto, que outras pesquisas vindouras podem ser desdobradas no intuito de uma sistematização dos meios de hospedagem (também) como signo de hospitalidade urbana.

De modo que, do ponto de vista metodológico, poder-se-iam fazer aplicações em turistas e cidadãos das categorias e modelos de Kevin Lynch (suporte teórico das proposições de hospitalidade urbana de Lucio Grinover) em destinos citadinos que hipoteticamente possuem uma "praça" hoteleira considerável - tratam-se dos mapas mentais - que "medem" a frequência de citações de edificações de meios de hospedagem quando das "entrevistas" através de desenhos, se são ou não referências urbanas efetivamente "desenhadas" a ponto de identificar tais meios de hospedagem como marcos urbanos.

Discutindo-se de outra maneira, nota-se que essa manifestação de hospitalidade urbana e da cidade através de meios de hospedagem, faz-se de modo a recorrer a outras categorias de análise (tais como as teorias da urbanização de Kevin Lynch), não necessariamente próprias aos estudos correntes de hospitalidade. Com isso, procurase enfatizar os conteúdos de hospitalidade citadina; diante da necessidade de mais evidências teóricas construídas por uma epistemologia da hospitalidade urbana.

Nesse sentido, do ponto de vista de uma epistemologia para a hospitalidade urbana, os estudos devem se atentar também para o caráter que o espaço possui como contribuinte, uma vez que pesquisas estão se fazendo pelo valor essencialmente social que a hospitalidade encerra em suas definições e conteúdos. Deve-se valer, então, do papel que o espaço pode conferir numa explanação para o fenômeno da hospitalidade, tais quais as disciplinas da geografia ou da urbanização já o fizeram a partir do ideal de uma dialética sócio-espacial (Soja, 1993; Lefebvre, 1991).

De qualquer forma, a verificação de conteúdos espaciais como atributo de hospitalidade urbana através dos meios de hospedagem podem se desdobrar em qualificação das destinações turísticas citadinas, na melhoria do espaço urbano e turístico. De sorte que se pode concluir que a qualidade de uma cidade como destino turístico também pode se dar pela quantidade e qualidade de seus meios de hospedagem enquanto imagem e paisagem urbanas.

Sendo a cidade, enquanto imagem e paisagem urbanas, "exposta" a todos (sejam cidadãos ou turistas) e, portanto, sem "cobrar" nada por isso; dotada de edifícios de meios de hospedagem que propõem identidade, simbolismo, hospitalidade; pode-se então pensar num ideal de que há uma hospitalidade genuína (e não somente "empresarial") por parte destas edificações.

Se a imagem do destino e a percepção da hospitalidade do destino é o hotel, então muitos hotéis podem ser o próprio destino; assim, a percepção da imagem do destino pautada em hotéis também pode ampliar uma compreensão cognitiva do turista na escolha do destino citadino turístico. Nessa perspectiva, planejadores e gestores 
do trade podem se amparar na identificação da hotelaria como imagem de cidade, porque dotada de hospitalidade urbana.

Se o hotel é um atributo de hospitalidade urbana, deve-se superar um maniqueísmo da ideia de que ele sempre foi historicamente destinado ao acolhimento de pessoas, ao descanso, à restauração e ao lazer; o hotel pode também promover relações de pertencimento e identidade a partir de sua imagem urbana. De modo que até mesmo as formas de classificação hoteleira, essencialmente baseadas nas instalações internas e nos serviços oferecidos pelo hotel, podem ser incrementadas com os valores de imagem urbana que um hotel pode proporcionar ao destino.

Pode-se interpretar que o incentivo ao turismo, entendendo-se a cadeia hoteleira como parte dele, poderia ofertar mais meios de hospedagem para um destino turístico; se o meio de hospedagem é uma condição de marco urbano, então ele "carregaria" a cidade de referências para a hospitalidade urbana. Ou seja, ainda que a empresa de meios de hospedagem seja uma iniciativa privada, ela poderia, por outro lado, condicionar uma melhor qualidade de imagem e paisagem urbanas, tornando o destino "carregado" de hospitalidade urba$n a$ - um benefício público - tanto para turistas como para cidadãos locais. Infere-se, portanto, sobre um processo de retroalimentação mútua entre o setor privado dos meios de hospedagem e a qualidade pública da imagem do destino (hipoteticamente) hospitaleiro, "alinhavados" e intencionados pelo mote do meio de hospedagem.

Os limites dessa pesquisa foram os que a motivaram: a falta de uma bibliografia que revelasse o papel da hospitalidade à escala da cidade e da paisagem urbana através de um meio de hospedagem.

\section{REFERÊNCIAS}

Ahn, T., Ekinci, Y., \& Li, G. (2013). Self-congruence, functional congruence and destination choice. Journal of Business Research, 66(6), 719-723.

Amposta, J. B. (2015). Tourism destination management: an overview of the advances of California. Tourismos, 10(2), 185-198.

Andrade, N., Brito, L., \& Jorge, W. E. (2000). Hotel: Planejamento e Projeto. SENAC: São Paulo.

Bareham, J. (2004). Understanding the Hospitality Consumer. International Journal of Hospitality Management, 23(1), 95-97.

Baptista, I. (2002). Lugares de Hospitalidade. In C. M. de M. Dias (Org.), Hospitalidade: Reflexões e Perspectivas. São Paulo: Manole.

Baptista, I. (2005). Para uma geografia de proximidade humana. Revista Hospitalidade, (2)2, 11-22.

Baptista, I. (2008). Hospitalidade e eleição intersubjectiva. Revista Hospitalidade, (5)2, 5-14.

Bastos, S., \& Rejowski, M. (2015). Pesquisa científica em hospitalidade: desafios em busca de uma configuração teórica. Revista Hospitalidade, 132-159.

Bell, D. (2007). Hospitality and Urban Regeneration in Hospitality: a social lens. Stirling: University of Stirling.

Barthes, R. (1971). Elementos de semiologia. São Paulo: Cultrix.

Buarraj, M. (2004). Arquitetura de Hotéis na Cidade de São Paulo. Dissertação de mestrado não publicada, Faculdade de Arquitetura e Urbanismo (FAU) da Universidade de São Paulo (USP), São Paulo, Brasil.

Boullón, R. C. (2000). Planejamento turístico. Bauru: EDUSC.

Camargo, L. O. (2005). Hospitalidade. São Paulo: Aleph. 
Camargo, L. O. (2015). Os interstícios da hospitalidade. Revista Hospitalidade, VII, 42-69.

Campos, L. C. de A. M., \& Gonçalves, M. H. B. (1998). Introdução ao turismo e hotelaria. Rio de Janeiro: SENAC.

Carvalho, P. D. da C., Salazar, A. M. P. L. V. B. K., \& Neves, J. M. de O. (2011). A imagem percebida e o perfil do turista de um destino turístico cultural: o caso do Alto Douro Vinhateiro, Patrimônio da Humanidade. FCHS (DCEC) - Artigos em Atas de Conferências Internacionais, 18.

Castelli, G. (2000). Excelência em Hotelaria: uma abordagem prática. Rio de Janeiro: Editora Qualitymark.

Cavalcanti, L., \& Guimaraens, D. (1982). Arquitetura de motéis cariocas: espaço e organização. Rio de Janeiro: Espaço.

César, P. A. B., Tronca, B., \& Mattana, B. (2017). A paisagem urbana e sua relação com o turismo - uma análise do Museu de Ambiência Casa de Pedra Caxias do Sul/RS. Ambientur - Simpósio sobre Gestão Ambiental de Empreendimentos Turísticos, III, n.d..

Chen, J. S, Ekinci, Y., Riley, M., Yoon, Y., \& Tjeiflaat, S. (2001). What do Norwegians think of US lodging services?. International Journal of Contemporary Hospitality Management, (13)6, 280-284.

Chon, K. S. (2003). Hospitalidade: conceitos e aplicações. São Paulo: Pioneira Thomson Learning.

Cruz, Rita de Cássia Ariza da. (2002). Hospitalidade turística e fenômeno urbano no Brasil: considerações gerais. In: Dias, C. M.M. (Org.), Hospitalidade: Reflexões e Perspectivas. São Paulo: Manole.

Dencker, A. M., \& Bueno, M. S. (2003). Hospitalidade: cenários e oportunidades. São Paulo: Pioneira Thomson Learning.

Dias, C. M. de M. (1990). Home away from home. Dissertação de mestrado não publicada, Ciências da Comunicação da Escola de Comunicações e Artes (ECA) da Universidade de São Paulo (USP), São Paulo, Brasil.

Dias, C. M. de M. (2002). Hospitalidade: reflexões e perspectivas. Barueri: Manole.
Donzel, C. (1989). Grand american hotels. New York: The Vendomi Press.

Duarte, V. V. (1996). Administração de sistemas hoteleiros: panorama histórico da hotelaria. São Paulo: SENAC.

Dumazadier, J. (1980). Valores e conteúdos culturais do lazer. São Paulo: SESC.

Furtado, S., \& Sogayar, R. (2009). Hospitalidade: um relacionamento global de conhecimentos e atitudes. São Paulo: LCTE Editora.

Garvin, David A. (1992). Gerenciando a qualidade. Rio de Janeiro: Qualitymark.

Gentile, C., Spiller, N., \& Noci, G. (2007). How to sustain the customer experience: an overview of experience components that co-create value with the customer. European Management Journal, 25(5), 395410.

Gibson, S., \& Molz, J. G. (2016). Mobilizing hospitality: the ethics of social relations in a mobile world. London: Routledge.

Gil, A. C. (2008). Métodos e técnicas de pesquisa social. São Paulo, Atlas.

Gotman, A. (2010). Villes et Hospitalité: les munícipes et leurs "étrangers". Paris: Éditions de la Maison de L'Homme.

Gotman, A. (2001). Le sens de l'hospitalité: essai sur les fondements sociaux de l'accueil de l'autre. Paris: Presses Universitaires de France.

Gouveia, D. (2013). Perfil e Motivação dos turistas praticantes de surf na escolha do destino Algarve. Statewide Agricultural Land Use Baseline, 2015, 1.

Grinover, L. (2007). A Hospitalidade, a Cidade e o Turismo. São Paulo: Aleph.

Grinover, L. (2006). A hospitalidade urbana: acessibilidade, legibilidade e identidade. Hospitalidade, (3)2, 29-50.

Grinover, L. (2003). Hospitalidade: um tema a ser reestudado e pesquisado. In A. D. F. M. Dencker \& M. S. Bueno (Orgs.), Hospitalidade: Cenários e Oportunidade (pp. 61-71). São Paulo: Pioneira Thomson Learning. 
Gu, Z. (2003). The Chinese lodging industry: problems and solutions. International Journal of Contemporary Hospitality Management, (15)7, 386-392.

Hatfield, E., Cacioppo, J., \& Rapson, R. (1994). Emotional contagion. Current Directions in Psychological Science, 2, 92-99.

Hemmington, N. (2007). From Service to Experience: Understanding and Defining the Hospitality Business. The Service Industries Journal, 27(6), 747-755.

Hosany, S., \& Martin, D. (2012). Self-image congruence in consumer behavior. Journal of Business Research, 65(5), 685-691.

Jacobs, J. (2003). Morte e vida de grandes cidades. são Paulo: Martins Fontes Editora Ltda.

Kamins, M. A., \& Grupta, K. (1994). Congruence between spokesperson and product type: a matchup hypothesis perspective. Psychology \& Marketing, 11(6), 569-586.

Knutson, B. J., Beck, J. A., Kim, S., \& Cha, J. (2009). Identifying the dimensions of the guest's hotel experience. Cornell Hospitality Quarterly, 50(1), 44-55.

Ladhari, R. (2012). The lodging quality: index: an independent assessment of validity an dimensions. International Journal of Contemporary Hospitality Management, (24)4, 628-652.

Lantos, F. (1977). Forma essencial de los viajantes de hoteles. Madrid: Hurtman.

Lash, S., \& Urry, J. (2002). Economies of signs and space. Londres: SAGE Publications.

Lashley, C. (2015). Hospitalidade e hospitalidade. Revista Hospitalidade, 12(esp), 70-92.

Lashley, C., Lynch, P., \& Morrison, A. J. (2007). Hospitality: a social lens. Amsterdam: Elsevier.

Lashley, C. (2004). Para um entendimento teórico. In C. Lashley \& A. Morrison (Orgs.), Em busca da Hospitalidade: perspectivas para um mundo globalizado. Barueri: Manole.

Latham, A. (2003). Urbanity, life style and making sense of the new urban cultural economy: notes from Auckland, New Zeland. Urban Studies, 40, 1699-1724.
Lefebvre, H. (1991). The production of space. London: Wiley.

Lockwood, A., \& Jones, P. (2002). The Management of Hotel Operations. New York: Cengage Learning.

Lynch, K. (2010). A imagem da cidade. São Paulo: Martins Fontes.

McNeil, D. (2008). The hotel and the city. Progress in Human Geography, 32(3), 383-398.

Mauss, M. (1974). Ensaio sobre o dom: sociologia e antropologia. São Paulo: Editora Pedagógica e Universitária Ltda./EDUSP.

Montadon, A. (2003). Hospitalidade: ontem e hoje. In A. D. F. M. Dencker \& M. S. Bueno (Orgs.), Hospitalidade: Cenários e Oportunidade. São Paulo: Pioneira Thomson Learning.

Montaner, J. M. (1997). La modernidade superada: arquitectura, arte y pensamiento del siglo XX. Barcelona: GG.

Monteiro, A. C. C. A. (2013). Os hotéis da metrópole. Evolução e história dos hotéis na cidade de São Paulo. Vitruvius. Recuperado em 06 julho, 2014, de http://www.vitruvius.com.br/revistas/read/arquitext os/06.062/444

Mohsin, A. (2007). Assessing lodging service down under: a case of Hamilton, New Zealand. International Journal of Contemporary Hospitality Management, (19)4, 296-308.

Motels, Hotels, Restaurants and Bars (1960). USA: Dodge Corporation.

Nailon, P. (1982). Theory in hospitality management. International Journal of Hospitality Management, 1(3), 135-143.

Oliveira, P. G. (2006). Pousada e território: um estudo da cidade de Tiradentes-MG. Dissertação de mestrado não publicada, Hospitalidade da Universidade Anhembi-Morumbi (UAM), São Paulo, Brasil.

O'Gorman, K. D. (2007). Dimensions of hospitality: exploring ancient and classical origins. In Hospitality: a social lens (pp. 17-32). Amsterdam: Routledge.

Oh, H., \& Jeong, M. (2010). Evaluating stability of the performance-satisfaction relationship selected lodg- 
ing market segments. International Journal of Contemporary Hospitality Management, (22)7, 953-974.

Oliveira, J. P. de, Tricárico, L. T., Velasquez, G., \& Gorski, B. (2015). Arquitetura Hoteleira sob a ótica da sustentabilidade e da hospitalidade do espaço: um estudo sobre a aplicação dos conceitos de sustentabilidade e hospitalidade do espaço em projetos de hotéis. Revista Brasileira de Pesquisa em Turismo, 10(1), 189-204

Otto, G. (2011). A nova era da arquitetura e decoração dos hotéis. Hotel News. Recuperado em 18 agosto, 2013,

de

http://www.printfriendly.com/print/v2?url=http:/hot eliernews.com.br/2011/11GabrielaOtto

Petrocchi, M. (2002). Hotelaria: planejamento e gestão. São Paulo: Futura.

Pezzotti, G. (2011). The essence of Hospitality and Service. In: M. C. Sturman, J. B. Corgel, \& R. Verna, The Cornell School of Hotel Administration on Hospitality: cutting edge thinking and practice (pp. 5-18). New Jersey: John Wiley \& Sons. Inc.

Pine, B. J., \& Gilmore, J. H. (1999). The experience economy: work is theatre \& every business a stage. Boston: Harvard Business School.

Pires, M. J. (1991). Hóspedes, hospedeiros e migrantes nos século XIX: raízes do turismo no Brasil. Tese de doutoramento não publicada, Comunicação e Artes da Escola de Comunicação e Artes (ECA) da Universidade de São Paulo (USP), São Paulo, Brasil.

Pires, M. J. (1991a). Hotéis do século XIX em São Paulo e no Rio de Janeiro - diversidade de serviços. Revista Turismo em Anális, 2(2), 55-64.

Pitt-Rivers, J. (2012). The law of hospitality. HAU: Journal of Ethnographic Theory, 2(1), 501-517.

Polizel, H. H. (2006). Sistema de classificação de meios de hospedagem por qualidade: um estudo exploratório descritivo. Dissertação de mestrado não publicada, Hospitalidade da Universidade AnhembiMorumbi (UAM), São Paulo, Brasil.

Raffestin, C. (2013). Réinventer l'hospitalité. Communications, Editions du Seuil, 65, 165-177.

Raffestin, C. (1997). Réinventer l'hospitalité. Communications, Editions du Seuil, 65, 165-174. Revista O Globo (2013). 9(458), 66
Roeffen, D., \& Grissemann, U. S. (2016). The importance of customer co-creation of value for the tourism and hospitality industry. In: Egger, R. Gula, I. \& Walcher, D. The open tourism: open innovation, crowdsourcing and co-creation challenging the tourism industry (pp. 34-46). London: Springer.

Rubino, S. (2009). Economia da experiência e o Turismo. In: Sogayar, R. \& Furtado, S. (Orgs.), Hospitalidade: um relacionamento global de conhecimentos e atitudes. São Paulo: LCTE Editora.

Sagi, L. C. (2008). Gestão pública da hospitalidade urbana: estudo de caso do Parque da Água Branca na cidade de São Paulo. Revista Brasileira de Pesquisa em Turismo, (2)3, 90-105.

Salles, M. R. R., Bueno, M. S., \& Bastos, S. R. (2014). Receber e acolher em São Paulo: desafios da hospitalidade numa feira boliviana, Kantuta. Revista Iberoamericana de Turismo, (4)1, 95-109.

Severini, V. F. (2014). Hospitalidade urbana: ampliando o conceito. Revista Iberoamericana de Turismo, $3(2), 84-89$

Soja, E. (1993). Geografias pós-modernas: a reafirmação do espaço na Teoria Social Crítica. Rio de Janeiro: Jorge Zahar.

Spolon, A. P. G. (2011). Hotelaria, Cidade e Capital. Tese de doutoramento não publicada, Arquitetura e Urbananismo da Universidade de São Paulo (USP), São Paulo, Brasil.

Stefanelli, M. M. C. (2015). Lugar de hospitalidade na cidade: acolhimento aos i-migrantes na missão paz. Dissertação de mestrado não publicada, Programa de Pós-graduação em Hospitalidade da Universidade Anhembi-Morumbi (UAM), São Paulo, Brasil.

Stefanelli, M. M. C., \& Bastos, S. M. (2016). Missão Paz: Lugar de Hospitalidade e Acolhimento aos IMigrantes na Cidade de São Paulo. Rosa dos Ventos, 8(3), 256-273.

Tasci, A., \& Semerad, K. (2016). Developing a scale of hospitableness: a table of two worlds. International Journal of Hospitality Management, 53, 30-41.

Tricárico, L. T., \& Gastaldi, P. (2015). A cidade construída pela imagem urbana: hotéis na praia de Copacabana (Rio de Janeiro, RJ, Brasil) como signo de lugares. Revista Estudios y Perspectivas en Turismo, 24(2), 244-263. 
Tricárico, L. T., \& Vargas, M. S. de (2017). Emoção como signo do espaço em meio de hospedagem. Caderno Virtual de Turismo, (17)1, 46-57.

Tricárico, L. T., Rossini, D. de M., \& Tomelin, C. A. (2016a). Automation in Luxury Hotel Architecture in Brazil and Argentina: An Overview of the Uses of Technology in Hotels in Latin American Contexts. The International Journal of Design Management and Professional Practice, 10(3), 7-16.

Tricárico, L. T. (2016). A Arquitetura Hoteleira como significado para sustentabilidade enquanto uso de recursos locais e sociais. TURyDES, 20, 1-8.

Tricárico, L. T., Rossini, D. de M., \& Tomelin, C. A. (2016). O significado do espaço como emoção: O hotel como signo: Hotel Semíramis, um caso. Razón y Palabra, (20)4-95), 566-590.

Tricárico, L. T., Rossini, D. de M., \& Tomelin, C. A. (2015). Hospitalidade espacial na hotelaria de Balneário Camboriú (SC): um estudo junto aos edifícios hoteleiros. Hospitalidade, 12(2), 600-625.

Tricárico, L. T. (2015). Justificativa do prazer e da emoção na hotelaria atual segundo Maslow. TURYDES, 18, 01-06.

Tricárico, L. T., Rossini, D. de M., \& Tomelin, C. A. (2014). Automação e arquitetura hoteleira: signos para aplicação de tecnologias da informação no espaço edificado enquanto geração de cogniçõe. In: Serra, Afonso, F. C. \& Santos, . (Eds.), Abordagens contemporâneas em Hotelaria e Restauração (pp. 37 50). Faro, Editora da UAlg ESGHT.
Tricárico, L. T., Rossini, D. de M., Oliveira, J. P. de, \& Miranda, P. S. (2013). Inovações em hotéis: emoção, sustentabilidade e automação como signo da arquitetura contemporânea. In: Henriques, C. (Org.), Inovação e qualidade na hotelaria (pp. 59-72). Faro, Editora da UAlg ESGHT.

Tuan, Y-F. (2013). Espaço e lugar: a perspectiva da experiência. São Paulo: Eduel Campos.

Vasconcelos, E. (2002). Complexidade e pesquisa Interdisciplinar. Petrópolis: Vozes.

Wada, E. K. (2003). Reflexões de um aprendiz de realidade. In: Dencker, A. D. F. M. \& Bueno, M. S. (Orgs.), Hospitalidade: cenários e oportunidades (pp. 61-71). São Paulo: Pioneira Thomson Learning.

Walker, J. R. (2002). Introdução à Hospitalidade. Barueri: Manole.

\section{Dados dos autores}

\section{Luciano Torres Tricárico}

Universidade do Vale do Itajaí (UNIVALI), Balneário Camboriú, SC, Brasil.

\section{Josildete Pereira de Oliveira}

Universidade do Vale do Itajaí (UNIVALI), Balneário Camboriú, SC, Brasil.

\section{Diva de Mello Rossini}

Universidade do Vale do Itajaí (UNIVALI), Balneário Camboriú, SC, Brasil. 